\title{
ENGLISH AS A WE-CODE: \\ FORM AND FUNCTION OF ENGLISH IN FACEBOOK STATUS UPDATES OF NON-NATIVE FEMALE AND MALE USERS
}

\author{
MARTA DAZBROWSKA \\ Jagiellonian University, Poland \\ marta.b.dabrowska@uj.edu.pl
}

\begin{abstract}
The English language has featured markedly as a popular language of computer-mediated communication, and notably of Facebook posts, written not only by native or second language speakers, but also users of English as a foreign language. The aim of this paper is to investigate the frequency, form and function of English language Facebook profile updates of 110 ( 55 women and 55 men) users of English representing 41 European, Asian, African and Latin American countries belonging to the Expanding Circle. Approached from the point of view of the code choice as well as the users' gender, and supported by an online survey data, the study analyses in detail the form of the updates in connection with gender preferences and identifies language contexts and functions users choose to express themselves in English as opposed to their native tongue, thereby demonstrating the role of English as a we-code in a social networking service.
\end{abstract}

Key words: English in the Expanding Circle, code choice, genderlect, computer-mediated communication

\section{Introduction: globalisation, social media, and choosing a code}

The present paper has been triggered by the observation of the ever more frequent tendency visible on social media of reading or writing posts or updates in a language that is not the users' mother tongue. This is an example of what Blommaert (2010: 102) describes as the use of truncated repertoires, which he defines not as "as a collection of 'languages' that a speaker controls, but rather as a complex of specific semiotic resources, some of which belong to a conventionally defined 'language', while others belong to another 'language."' The phenomenon, often observed in western European countries that have attracted a large migrant influx, which consequently results in the use of numerous tongues induced by interaction with different people on a daily basis, is also to be found on social media, and notably also on Facebook, the most popular social networking platform of the present day. In the contemporary world of excessive mobility and making acquaintances quickly, even when not having met in person, people develop a large network of friends who they want to stay in touch with. As Tagg and Seargeant (2014) point out, in the modern 
world there exists a possibility of creating a sense of intimacy even when addressing an audience at the global level, and it can be achieved by means of writing in a particular way or using particular languages (cf. Deumert 2014). Social networking sites make this task relatively easy. However, when users have contacts both in their own country and abroad, they face a dilemma as to which language they should phrase their updates in - the native one, a foreign one (and if so, which?) or - both? Studies show that although the share of English-medium websites is diminishing when compared to the onset of the Internet, when it reached 85\% (cf. Graddol 2006), social networking sites witness a loss of other tongues in the face of the use of English as a global lingua franca. English has become a common means of communication both when writing and responding to posts (Deumert 2014).

The question of language choice under various circumstances has been an object of sociolinguists' study particularly since the time of the publication by Blom and Gumperz (1972), in which observations about the code choice in a Norwegian village of Hemnesberget were presented, and subsequently also the division of code switching into a situational, conversational and metaphorical type, the latter a redefinition of the conversational type (cf. Gardner-Chloros 2009), was first introduced. Metaphorical code switching is of particular interest, as the switching itself is not a result of any change in the external situation, but in fact the reason for the switch. By shifting between the available tongues the users are able to redefine the situation and switch from a formal to an informal reading of it, "official to personal, serious to humorous, and politeness to solidarity" (Wardhaugh 1992: 107). Thus the division can very broadly be seen in terms of style and audience design, resulting from the relationship between the interlocutors and the situation they find themselves in (cf. Bell 1984).

There is thus an additional type of message conveyed by the choice of the language side by side with what the interlocutors communicate by means of words, one that defines the current situation. Following this additional reading of a message Gumperz (1982) introduced a division into the we-code, which stresses the sense of closeness and solidarity between the users, a marker of the in-group membership, and the they-code, which marks a distance between users, formality and a sense of out-group membership. A reflection of this interpretation could later be to some extent found in Myers-Scotton's (1993) Markedness Model, with the unmarked choices being those expected, and hence solidarity-driven ones, and the marked choices stressing some differences and distance between the users. However, linguists emphasise (cf. Wardhaugh 1992, Sebba and Wootton 1998) that the division between one code being we-oriented and the other they-oriented is by no means fixed and absolute, and certain choices themselves define the context. What is more, some topics may be discussed in both codes, or their traditional roles may be reversed, e.g. typically, the minority language in a given community is perceived as a we-code, and the majority language carries the out-group connotations, yet occasionally, as e.g., 
in India, speakers with higher social aspirations may assume English as their wecode and Hindi - as they-code, and thus manifest their own departure from the generally accepted norm (cf. Gardner-Chloros 2009). For some speakers two codes that they use may both constitute we-codes, as e.g. London English and London Jamaican for Black British speakers (ibid.), as the use of both is what defines that speech community. A similar interpretation may be linked with one of Myers-Scotton's (1993) elements of the Markedness Model in which the actual switching between two codes, e.g. English and Swahili in Kenya, is normal, neutral and therefore expected, and thus a series of switches in itself constitutes a we-code.

It is not too difficult to translate these observations into the present-day electronic communication context, which goes beyond the concept of the traditional speech community, leaning more towards the notion of the community of practice or, more appropriately, virtual community (cf. Wenger 1998, Eckert and McConnell-Ginet 1992, Seidlhofer 2007). Eckert and McConnell-Ginet (1992: 464) define it as "aggregate(s) of people who come together around mutual engagement in an endeavour." Wenger (1998: 72-73), the proponent of the concept, claims that the primary criteria for such communities are "1. mutual engagement in shared practices, 2. taking part in some jointly negotiated enterprise, and 3. making use of members' shared repertoire." Thus, one of the features of the community of practice is a shared repertoire (cf. Trousdale 2010), and this, as the observation of the multilingual world shows, does not have to be limited to one code. In the context of the growing use of English as an international language resulting from its ever more widespread use, which has led to its visible diversity worldwide, best known from the classification into, among others, the Inner, Outer and Expanding Circles postulated by Kachru (1992), which correspond to English as a native, second or foreign language, respectively, English has become an ever more utilised and nativised element of everyday communication also in the countries where it has no established speech community (cf. Trousdale 2010). Its practical role as a medium of international communication and a growing symbolic status (cf. Pennycook 2007, Blommaert 2010) can be seen in the communication patterns users exceedingly employ in the electronic medium as a part of their linguistic repertoire - as a we-code. In his study of language choice Hinrichs (2006, after Dorleijn and Nortier 2009: 134) demonstrated that the unmarked language in daily CMC use was English. The present study aims to provide further proofs of this claim, particularly in relation to Facebook users from the Expanding Circle, as well as to explicate details of their use of English with respect to its form and function, additionally analysed from the point of view of the users' gender.

The phenomena of code choice and code-switching (code-mixing), though often used interchangeably, for the purpose of the present study will be understood as, regarding code choice, a decision to write a post in one language as opposed to the other (e.g. one's native language or English), in contrast to the 
use of two or more languages in one post, i.e. code-switching. Code choice and code-switching have been studied in numerous contexts over the years, particularly in respect of the character and frequency of use as well as function of languages in bi- and multilingual setting (e.g. Gardner-Chloros 1991, MyersScotton 1993, Treffers-Daller 1999, Clyne 2003, etc.). The variable of gender in relation to code-switching has been given particular focus, among others, in the studies by Cheshire and Gardner-Chloros (1997, 1998), Gardner-Chloros and Finnis (2004), or Poplack (1980), and in recent years there has been an increased attention paid to the function of code-switching employed by women and men in non-western societies, mainly in spoken communication (cf. Ismail 2015, Panhwar et al. 2018, Al Kaddour and Kaddoura 2019). The question of code choice in written communication in relation to the variable of gender has, on the other hand, been analysed, among others, on the basis of text messaging (Mushtaq 2012, Bassam 2017). The innovation that the present study introduces is to incorporate the investigation of code-choice with a particular focus on gender differences in the context of the social media with the aim to broaden the sociolinguistic perspective on the use of English as an international language in CMC with the underlying assumption that the gender of the social media users will have a bearing on the frequency and character of the language choice.

\section{Methods and data}

In order to research the frequency of the use of English in the profile updates of English as a foreign language users and investigate the posts composed in English in terms of their form (i.e. their length, use of different codes as well as non-linguistic elements in the update) and function, i.e. particularly the topics that English is employed to express, the analysis will consist of two steps. The first aspect will involve the presentation of the users' own perception of their language choices employed in Facebook profile updates, investigated by means of an online survey. The second element will be the analysis of the actual data collected from the Facebook users' profiles, as these represent the owners' personal choice and are not motivated by the language of someone else's posts that they may wish to respond to. These will be discussed with a particular attention paid to the users' gender. Based on their form and function, the uses of English will be classified into code-switches (uses of English together with other languages in one post), one-sentence updates, multi-sentence updates, and quotes, which is a classification that reflects a progressive degree of difficulty concerning the use of a foreign language in a written form, and will further be discussed with regard to who the updates are directed to (personal vs. impersonal addressees) and what topics (subjective vs. objective) are discussed by means of English. 


\subsection{Participants}

The analysis of the data excerpted from Facebook will be illustrated by examples of profile updates found on the walls of altogether 110 persons, randomly selected, all of them belonging to Kachru's Expanding Circle (1992). The respondents, personal contacts of the author of this paper, who have been known to use English, altogether represented 41 countries, the majority of them from Europe, with a selected number of countries in Africa, Asia and Latin America. The list of the countries included in the study covers, alphabetically: Albania, Armenia, Belarus, Belgium, Bosnia, Brazil, Bulgaria, Colombia, Croatia, Czech Republic, Denmark, Egypt, Ethiopia, Finland, France, Germany, Greece, Holland, Hungary, Indonesia, Israel, Italy, Japan, Latvia, Lebanon, Lithuania, Malta, Moldova, Norway, Poland, Portugal, Romania, Russia, Serbia, Slovakia, Slovenia, Sweden, Taiwan, Ukraine, and Uruguay. In the case of some countries, notably: Albania, Belarus, Denmark, Egypt, Finland, France, Germany, Holland, Malta, Moldova, Norway, Poland, Sweden, Taiwan, and Ukraine (15 states) it was possible to find data from both a male and a female user of Facebook, which is an important aspect of the study which aims to investigate the tendencies accounting for the choice of language in terms of the gender of the profile owners. Altogether, even though not all the countries are represented by both men and women, the whole sample of respondents is evenly divided into 55 women and 55 men, which will allow us to make some broad genderlect generalisations in the specific context of their online social networking behaviour (cf. Mills and Mullany 2011).

In the case of each person investigated 5 most recent posts were taken into consideration, as a result of which the overall number of posts analysed for this study reached 550, respectively, i.e. 275 for men and 275 for women. The collected sample comes from the period between December 2014 and May 2015, yet, as the online survey data of the 44 respondents show, the users update their profiles at various intervals (i.e. $11.4 \%$ of them - every day, $34.1 \%$ - a few times a week, $25 \%$ - a few times a month, and $29.6 \%$ - a few times a year), therefore the posts scanned cover quite diverse stretches of time

\subsection{Survey results}

Before the actual updates are analysed, a reference will be made to the survey results. The survey was filled out by 44 members of the original sample group (21 men and 23 women, between the age of 26 and 65, with the majority of respondents representing the age brackets between 26 and 35 ( 15 persons) and 36 and 45 years of age (12 persons). According to the users' own evaluation, only $9.1 \%$ of them (4 persons) write their updates in their native tongue alone, $13.6 \%$ (6) only in English, 13.6\% (6) in some other tongue, whereas 75\% (33 persons) indicated both their native tongue and English as the language of their profile updates (the sum total of the resulting figures shows that some 
respondents ticked more than one option listed in the questionnaire, which will be visible in other questions discussed below too). These findings largely corroborate the distribution of the investigated updates below. Moreover, as regards the form and length of the posts in general, the respondents indicated that their updates consisted of: a) a couple of words $(25 \%$ - 11), b) a full sentence $(25 \%-11)$, c) a couple of sentences $(40.9 \%-18)$, d) only a photo $(27.3 \%$ - 12$)$, e) only a link to some website $(22.7 \%$ - 10). When asked specifically about their updates in English, only two (4.5\%) responded that they never wrote them in English, whereas 25\% (11) wrote only short texts of a couple of words, $27.3 \%$ (12) - in a form of a sentence, and $43.2 \%$ (19) in a couple of sentences. In the overview of their own language choices on Facebook the respondents also said that the dominant language of their updates was: a) their native tongue 50\% (22 persons), b) English 52.3\% (23), c) some other language $2.3 \%(1)$, and d) two $(4.5 \%)$ could not answer the question. What is more, only for $25 \%$ (11) of them was the choice of the language on Facebook automatic, for the other $75 \%$ (33) it was a conscious decision.

When asked about their reasons and motivation to write in their native language the respondents ticked the following options:

\begin{tabular}{|l|}
\hline when I write about some local issues $-32(72.7 \%)$ \\
\hline because most of my Facebook contacts speak my own native language $-13(29.5 \%)$ \\
\hline because I feel most comfortable expressing myself in my native tongue $-7(15.9 \%)$ \\
\hline because I feel most comfortable writing (spelling) in my native tongue $-3(6.8 \%)$ \\
\hline because I am against the growing presence of English in the electronic media $-2(4.5 \%)$ \\
\hline because my knowledge of English is too limited $-0(0 \%)$ \\
\hline other - $6(13.6 \%)$
\end{tabular}

Thus, it can be seen that in the users' own evaluation it is mostly the topic of the update, and much less the recipients, next to some more minor reasons, that decide about the choice of the native tongue in the updates.

Alternately, when asked about their selection of English as the language of their updates, the users ticked the following options:

\begin{tabular}{|c|}
\hline because English is the international language of today's world - $18(45 \%)$ \\
\hline because all my Facebook contacts are foreigners $-14(35 \%)$ \\
\hline because English is a part of my Facebook identity $-8(20 \%)$ \\
\hline because it feels most natural to use English on Facebook $-8(20 \%)$ \\
\hline because I feel most comfortable expressing myself in this language - $7(17.5 \%)$ \\
\hline even though my Facebook contacts come from my own country $-7(17.5 \%)$ \\
\hline because English feels more suitable for the electronic medium $-6(15 \%)$ \\
\hline because I want to practice English $-5(12.5 \%)$ \\
\hline I can express my emotions and attitudes better in English $-5(12.5 \%)$ \\
\hline because it is expected to use English on Facebook - 2(5\%) \\
\hline because it creates a sense of belonging to this group of friends $-2(5 \%)$ \\
\hline because I can be a different person when I write in English $-0(0 \%)$ \\
\hline because I feel a more attractive person when I write in English $-0(0 \%)$ \\
\hline other $-8(20 \%)$ \\
\hline
\end{tabular}


The above shows that although the majority indicated a practical reason of their choice - that is the foreign background of their friends, quite a visible proportion revealed that they do it also when their friends are of the same nationality. Also, a significant element of the answers is the fact that English is the international language of the world, but also a part of their Facebook identity, that it is natural and expected to use English in the network, what is more, that it is a suitable tongue for the medium.

Additional remarks provided by the respondents in the survey indicate that, apart from the most frequent reason being the practicality of the use of English in order to address the recipients who are of foreign nationality and mostly do not understand the respondent's native language, what also needs to be noticed are, respectively, the topic of the post, the fact that English is a lingua franca of today's world, the lack of applications in the native language, and also the fact that it is easier to summarise things in English, because it sounds shorter, faster and funnier, as well as the conclusion that English has grown to be a huge part of the respondent's life. The latter observations are obviously only quoted once or twice, yet their very presence is also indicative of the role of English and the way people perceive it and apply in the modern world.

Finally, when asked about the form of the posts, and notably the choice of language in them, the respondents indicated what follows:

\begin{tabular}{|l|}
\hline I often write the same text in two languages, my own and English $-12(27.3 \%)$ \\
\hline I do not care about their form, no matter in which language I choose to express myself - \\
$8(18.2 \%)$ \\
\hline I often switch back and forth in the sentence between my own language and English -7 \\
$(15.9 \%)$ \\
\hline I am always concerned that I will make a mistake in English, so I do not use this \\
language very often $-3(6.8 \%)$ \\
\hline none of the above $-17(38.6 \%)$. \\
\hline
\end{tabular}

The samples of updates analysed in the present study do not necessarily show such a large percentage of posts written in the two languages as indicated in the survey data above, and neither do they manifest code-switching to such a degree as indicated in the users' answers. It needs to be acknowledged, however, that they only cover a sequence of 5 posts, they are, therefore, naturally not so representative of all the updates produced. When asked about the topic of their last 5 updates in English, the respondents themselves suggested a number of options. Their overview led to a conclusion that a frequent topic of posts in English were some international events, politics, social work, and also local developments, yet of an international appeal or importance. Likewise, a significant share of the comments denoted everyday affairs, cultural and sports events, as well as free time activities. 


\subsection{Analysis of profile updates}

The overview of the updates demonstrates that more than a half of these were composed in English: men wrote 140 posts in English (51\%) and 135 (49\%) in their native tongues, whereas women produced updates in English 154 times (56\%) and 121 in their native languages (44\%). Thus, there were more updates in English than in the native tongues in both groups, with, however, a slight preference of women in this respect. Naturally, broken down into details, these results do not prove to be so neatly distributed across the two genders. Among the 55 women investigated there were 6 who never used English in their last 5 updates investigated (whereas only 4 such men were found in the sample of $55 \mathrm{men}$ ), at the same time there were also such that always used English in their updates. The figures in between were distributed as follows: a) 1 message in English out of 5-17 women and 16 men, b) 2 messages - 9 women and 6 men, c) 3 messages - only 7 women and as many as 13 men, d) 4 updates only 6 women and 10 men. Thus, altogether 10 women and only 5 men put all their updates in English. On top of that, 11 men made use of code switching in their profile updates (all of them once, except for one man, who used it as many as 7 times, and, contrary to the majority of one-word switches, in the form of full sentence posts), as well as 10 women, who did it mostly once, maximum twice in the collected samples (the overall number of switches would be, for men -17 , and for women - also 17).

The below subsections will present the division of the collected data into the categories in terms of their form and content, and their analysis will be offered in the discussion part (section 3).

\subsubsection{Code switches}

As regards the form of the posts, it is the switches that will be analysed first as a kind of a compromise between the native and the English language updates. Switches were altogether identified 34 times in the 550 updates, equally divided between men and women. However, their form varied, therefore they need to be divided into at least two broad groups. The first, and the easiest one, will comprise examples which would take a form of one word, possibly one noun phrase, e.g. women: a) kdy naši prátelé použiji tlačitko ,like “ nebo „comment" (Czech Republic); b) Simply: per un felino la vita deve essere divertente!!!! (Italy); c) Desigur va fi prezenta si o masuta de la Eco-village Moldova! (Moldova); d) Если это не про нашу жизнь, то wtf?:))) (Latvia); and men: a) Soviel zum Thema Fixie - hilarious! (Germany); b) (4/4 pour les derniers exam plateau, circu ... Yess !!) (France).

A more complex type of switches, visually, are the switches involving full sentences, as in the examples below, written by, respectively, women: a) Sretan Uskrs / Vrolijk Pasen / Happy Easter (Holland); b) Happy Mother's Day! Schönen Muttertag! Bonne fête des mères! С Днём Maтерu! đinnhuuцnn 
Uujpliph unnin (Armenia); c) Shume faleminderit per urimet te dashur miq ma bete diten akoma me te bukur! Thank you so much my dear friends you made my Day (Albania); d) walking in a loved one's shoes..... sa umbi in papucii cuiva care te iubeste.... (Romania); and men: a) Run for unity!! - Corrida por la unidad!! (Uruguay); b) Some 30 strawberry seedling planted, some summer veges sown and new fruit trees planted. Feeling happy but sore. 30 uutta mansikantainta istutettu, porkkanaa lehtikaalta yms kylvetty. Istutettu kaksi luumupuuta ja tyrniä. Lihakset huutaa aroma (Finland).

\subsubsection{One-sentence updates}

The next subcategory in terms of the form of the updates is a group consisting of one sentence in English. Altogether, there is no marked difference between men and women in terms of the frequency of choosing this form of updates - women used 69 out of 154 updates, which makes it $44 \%$ of all their English medium posts, and men - 64 examples of such a form out of 140 (i.e. $46 \%$ of all their English updates). However, a further distinction needs to be introduced in this category - one will be labelled as "pure updates," as opposed to "photo captions," when the actual update consisted of a photo or a link with some description or explanation of it.

The overview of the one-sentence caption category shows that not infrequently is the caption verbless or has a form of a sentence equivalent, with the use of a non-finite form. The descriptions of photos, occasionally links to songs, etc., tend to be short, usually in the form of an additional comment on what can be seen or what demands some explanation. And thus, in the case of women the photo captions often take the following form: a) Coming back from holidays end of July 2014 (Albania); b) Sisterhood time (Armenia); c) Snoopy forever! (Greece); d) The big fork of Vevey (Romania); Psalm 136 (Ethiopia); e) Amazing images (Portugal); f) Scary (Holland); g) Liiiiike !!! (Lebanon); h) Worth seeing! (Malta); i) Irresistible charm (Poland); j) On my way to university, board in the trunk!!!! (France); k) To dive or not to dive or... (Finland); 1) Beautiful Riga!:) (Latvia); m) Lovely sunset (Belarus); n) no words, just impressions (Moldova); o) no comment (Slovakia). In the case of men, on the other hand, the one-sentence captions can be represented by the following examples: a) The Monte Carlo Casino (Holland); b) Fall leaves (Belgium); c) The cat looking innocent (Switzerland); d) Polish and Ukrainian online for free (Ukraine); e) Looking for the eternal sunshine of spotless mind (Indonesia); f) Home Sweet Home (Taiwan); g) Post-modern cloakroom (Poland); h) worth reading (Germany); i) Very much true (Egypt); j) Some rules to think of!!! (Malta); k) Sailing home (Sweden); 1) Interesting! (France); m) Try that, dudes... (Slovenia).

The remaining posts are more complex, primarily in the sense that they consist of a proper sentence. The difference here is that since the update consists of only the text part, and has no additional source of information in the visual or audio form, it has to be informative enough for the reader to understand what 
the author is trying to communicate (although naturally posts which are short, even one-word updates, can also be found). The representation of this subcategory of updates, with the division into the females' and males' posts is presented below:

Women: a) All is well $\odot$ (Serbia); b) Dear friends in London, do not miss the floating films this weekend!!!! (Czech Republic); c) Your days go the way you start them (Ukraine);

Men: a) Wake up, People of the Earth... (Slovenia); b) All the Finns go to forest, lot of mushrooms are waiting for you (Finland); c) Heading for London (Egypt); d) You can't change the world, but how about your belt? (Poland); e) Back to Beirut (Lebanon); f) It is going to be another loooooong day today! (Switzerland); g) go live... (Hungary); h) Good morning (Malta).

\subsubsection{Multi-sentence updates}

The following subcategory of the formal description of the updates are posts which consist of more than one sentence. As could be deduced above, such posts were numerically less frequent than the one-sentence updates, be it used individually or along with a photo. When it comes to the multi-sentence updates, altogether they would be divided into 68 updates produced by women $(45 \%$ of all the collected women's updates) and 59 updates written by men (i.e. $42 \%$ of all the form-related types).

- photo captions:

Women: a) We don't say "goodbye", we say "see u soon". See u soon, friends!!! We had a wonderful time together (Belarus); b) can't believe it's already 17 years since this song was released...it still sounds massive (Poland); The countdown's on. Concert time in Ih40min! (Germany); c) During this evening we celebrate Nepal and support its people. Jimmy Nelson, well-known photographer, tells about his experience in Nepal (Holland).

Men: a) If you have time to have a look on this site, maybe you'll feel it worth doing something. After a lot of hesitations, I finally signed it (Switzerland); b) One does not simply walk to Mordor, they said... they even illustrated it! So I checked. You could. It's half a mile. And both lie in Kraków. I've always maintained Kraków *is* Middle Earth (Poland); c) Only human can arrive to this and demand it is a right. Are we on our way to destruction???? (Malta); d) Good morning Berlin, ready for a nice round of skiing/skating....after a roll with honey from my neighbors bee hives (Germany).

- pure posts:

Women: a) Wow, what a month! Blessed to carry in my heart priceless memories from wonderful people at Caux! A unique experience indeed! (Bosnia); b) First time in my life i'm watching president's speech! tears in my eyes and faith in heart. Ukrainian anthem volumed up (Ukraine); c) It's time to visit the magic mountain where many lives get changed. Has been 22 years since my first visit, and always new things happen and will continue, for sure 
(Latvia); d) A huge thank you to all my friends out there. You made my day!!! (Switzerland); e) Dear Friends and Family, Thank you very much for the lovely messages on my birthday! I have had a normal day of work guiding. I had nine nationalities among thirty one guests. The day is not over yet! (Malta)

Men: a) After a good long discussion today, remembered about the most fulfilling sentiment I've ever experienced - that of helping others to find some light in their lives... (Moldova); b) Thank you all for your wishes for my birthday! Early this morning at 7.30 I took part in an ecumenical celebration at "La Défense" (The Paris business and industrial centre). In this thick crowd, I still managed to meet four people I knew! As we returned at 8.30, encouraged by spontaneous choirs, we sang hymns in the metro (not very common in Paris). By the way, Happy Easter to you all (though late in the day) (France).

\subsubsection{Quotes}

A different use of English in the analysed posts, although much more limited compared to the above-mentioned functions, is that of quoting other sources.

Women quoted, among others, what follows:

a) Love is an open dooooooooooooooooooooooooooooor (Germany); "If I can unite in myself, in my own spiritual life, the thought of the East and the West, of the Greek and Latin Fathers, I will create in myself a reunion of the divided Church, and from that unity in myself can come the exterior and visible unity of the Church. For if we want to bring together East and West, we cannot do it by imposing one upon the other. We must contain both in ourselves and transcend both in Christ." Thomas Merton (Norway); b) "It's the mortar, not just the bricks, that makes a building strong. The mortar, in a strong team, is social capital: mutual reliance, an underlying sense of connectedness that builds trust." - Margaret Heffernan (Holland).

Men, on the other hand, cited, among others, the following:

a) if all could love like you and me, Imagine what the world could be... (Belarus); b) "The Stanislavski method is a very big shit" Philippe Gaulier (Brazil); c) Tomorrow never dies... (Poland); d) "Anxiety is the fundamental mood of existence" Attributed to Heidegger (Albania); e) The Big Mac index: Oily and easy $\mid$ The Economist (Switzerland).

\subsubsection{Addressees of the updates}

There are a few other aspects of the form of the updates to analyse. One concerns the way the users shape the posts in terms of whether they take on the more personal or impersonal form with respect to the addressees of the posts, in other words, whether they give them the $2^{\text {nd }}$ person form (mostly plural, occasionally singular), or a more general $3^{\text {rd }}$ person form. The analysis of the posts has revealed that $23 \%$ of women's posts ( 35 out of 154 ) and $27 \%$ of men's updates (38 out of 140) had a form of a more direct address, contrary to the general comments, statements and descriptions of what could be seen in the 
photo and link captions. Some illustration of the women's and men's choices can be seen below:

Women: a) Dear friends, I am sorry if you discovered a video from me yesterday. "Guy - my fantazy". It was not meant to be sent. I am not aware about sending it. Just trying to delete it. $M$ (Czech Republic); b) Anyone in need of a stroller? Quite used, but still good to go. Free. (Moldova); c) Dear friends! Thank you so much for remembering me on my birthday. Each greeting brought back some nice memories. This is how I celebrated it (Latvia); d) A huge thank you to all my friends out there. You made my day!!! (Switzerland); e) Thanks so much for all your birthday wishes. I had a wonderful birthday evening, with many friends around. (Germany); e) Happy mother's day mama! Deeply grateful for all that you taught me and continue to do, for your everlasting care and love. Big virtual hug and kiss to you in the States right now. I love you! (Holland); f) Please watch this I promise you that it will touch your life and hopefully make a difference (Israel); g) It's been a great year! Thanks for being a part of it (Ethiopia); h) My dear friends, I would like to ask you to post me of any event happening over next week...my friend from England has arrived, he is a professional photographer and he wants to cover as many events as possible. Thank you (Armenia); i) Thank you so much my dear friends you made my Day (Albania).

Men: a) Wake up, People of the Earth... (Slovenia); b) if all could love like you and me, Imagine what the world could be... (Belarus); c) All the Finns go to forest, lot of mushrooms are waiting for you (Finland); d) If you have time to have a look on this site, maybe you'll feel it worth doing something. After a lot of hesitations, I finally signed it (Switzerland); e) If you agree, like and share (Malta); f) It is up to you to make it this year to the unique conference place in the heart of switzerland. Sign up for conferance now! (Germany); g) We invite you to a very special event on Sunday June the 29th at 12:00 (Poland); h) for young Daddy, This video is for you. Happy Daddy for happy Children (Indonesia); i) for all my friends, i`m sorry if you got such porno photos, $i$ have got a virus in my page (Egypt); j) Run 4 Unity!!! (Uruguay); k) go live... (Hungary).

\subsubsection{Topic of the posts}

The next aspect to be considered is the function of the collected English-medium language samples. In other words, the focus will be put on what kind of meanings the users from the Expanding Circle pass on to their friends on Facebook by means of English. Following the line of description assumed by Dąbrowska (2013) the division of the collected posts will be made in the first place into subjective vs. objective topics, in order to see what the general tendencies on Facebook topic-wise are, especially with regard to women and men, notably when they use English as a foreign language. 
The background of this division - self vs. the world will be understood broadly on the basis of whether the topic of the post revolves around the author and his/her life, experience, impressions, or whether it is made fairly objective and deals with some world issues, events which have no direct application to the author's immediate experience. The overview will exclude the direct address (as yet a different function), which was analysed under the heading concerning its formal aspects ( $2^{\text {nd }}$ person pronoun) above.

Some samples of each of the subcategories collected for the present study are enumerated below:

Personal topics:

Women: a) We don't say "goodbye", we say "see u soon". See u soon, friends!!! We had a wonderful time together (Belarus); b) Love this flow of the inner beauty (Latvia); c) Happy, dressed up\& working hard at "Healing the Past" meeting (Ukraine); d) Some 30 strawberry seedling planted, some summer veges sown and new fruit trees planted. Feeling happy but sore (Finland); e) On my way to university, board in the trunk!!!! (France); f) A huge thank you to all my friends out there. You made my day!!! (Switzerland); g) Istanbul, I miss you... (Poland), h) Thanks so much for all your birthday wishes. I had a wonderful birthday evening, with many friends around. (Germany); i) Pretending being on summer holiday, it works :) (Norway); j) My favorite photos from DowntownMontreal. And an experience of being caught in a demonstration... :))) (Lebanon); k) Personally, I must have heard it at least 6 times since I first discovered it last summer. Over the past month or so, ... (Denmark).

Men: a) En route from Munich to Montreal (by chance - in business class) (Moldova); b) Sailing home (Sweden); c) Sleepless... too many thoughts... brainf**k (Switzerland); d) Heading for London. (Egypt); e) Home Sweet Home (Taiwan); f) Slightly depressed as I didnt get the job I was hoping for ... (Poland).

Impersonal topics:

Women: a) Great article from a friend of mine who experienced Ramadan for some days with us in Switzerland! (Bosnia); b) prayer for peace in holy land (Slovakia); c) Ten Minutes Older, a moving experiment for opening one's eyes to the emotional power of childhood innocence and curiosity (Romania); d) The little sun's rays are growing fast... (Moldova); e) And the original is here: (Ukraine); f) Babies learn from what they see, and this little cute one learnt how do to CPR ! (France); g) Next concert for Coin d'Parapluie: 18 April 2015 in La Cerlangue! (Germany); h) Berlin 1945. Mind blowing video (Israel)

Men: a) Life wisdom, beautifully put (Sweden); b) More giants from Mercè festivities. Barcelona (Brazil); c) A different vision - and prevision - of the Scottish referendum, and of the next to come (France); d) Urban landscape this morning... (Poland); e) Some rules to think of!!!!!! (Malta); f) "For a lead role in a cage".... Its sometimes a dream for lots of people (Egypt); g) There is enough for every ones need, but not for every ones greed. So let's be and act responsible for the sake of the disadvantaged.... (Germany); h) Post-modern 
cloakroom (Poland); i) Polish and Ukrainian online for free. (Ukraine); j) The cat looking innocent (Switzerland).

\section{Discussion}

The present section attempts to analyse the findings listed in the categories above in regard to the gender of the post authors. The first subcategory concerning code-switches shows updates coming in equal numbers from profiles of both women and men, which proves that there is hardly any marked difference in terms of gender in this respect. The switches presented here, if viewed from the point of view of theory of code switching, would mostly fit the category of extrasentential switches or tag switches (Poplack 1980; Nortier 1990). These are the simplest forms of switches as they involve the use of elements which stand outside the main structure of the sentence, like interjections, tags, side comments, also illustrated here. Apart from these we also do see some more challenging type of switches which could be either identified as intrasentential switches (Poplack 1980) or, after Muysken (2000), insertional switches. The latter term might be more appropriate here as the individual nouns/noun phrases, mostly in the form of a proper name, title, etc. are most likely quotes of names of events or some instructions (e.g. Eco-village Moldova, Challenging extremism, "like" or "comment"), in which case they may not even have a native equivalent, or it takes less effort to refer to them in the original form. This form is therefore not very challenging, either.

The overview of the second subcategory of switches also proves that apart from the length of the English elements, which do demand a good command of English of the profile owner, the switches are not risky to perform from the formal point of view. They all could be classified as intersentential switches (Poplack 1980), and thus coming after a full stop once the native sentence before, or after, is properly ended or introduced. The closer analysis shows that the examples collected here fall into two types. One could be classified as wishes, e.g. Easter or Mother's Day, and here the formulaic and symbolic character of the use of English is underlined by the sequence of the same type of expressions formulated also in other languages, not only the user's native tongue - thus stressing that the addressees of the message are all Facebook friends of the profile owner. It may likewise be claimed that this subcategory of switches is not challenging either, for such expressions as wishes may easily be obtained in different languages with the help of Google Translate or the like, in fact the person does not have to know these languages at all. By contrast, it is presumably somewhat different in the case of the few examples which are not occasional wishes and take the form of a more direct, personalised address or a caption under a photo. Clearly, the authors' intention here was to reach all their contacts with that specific piece of information (like thanking for the wishes, 
sharing information or some impression). This, as is confirmed by comments the users themselves provided in the survey referred to above, is a frequent reason of why they choose both their native language and English while writing on Facebook - in order to be able to reach all their local and foreign contacts.

By way of a final comment concerning code switching between the native language and English it needs to be pointed out that classical examples of intrasentential switching, or rather code-mixing, have not been recorded in the analysed sample. In the study by Dąbrowska (2013), where switches used by Poles and Indians, respectively, were compared, the number of intrasentential switches recorded for the Polish users was likewise very low, especially compared to the switches performed by Hindi speakers. It may thus be concluded that such switches are conditioned by a more intimate and frequent use of English on a daily basis, which is certainly the case in India as a country of the Outer Circle, whereas the fear of potentially making a mistake in the update (cf. the survey results) and violating some subconscious norms concerning the form of updates may act as a preventive measure in the case of the Expanding Circle users, and the idea of code-mixing in public may be viewed negatively too, as studies of code-switching often stress (cf. Wardhaugh 1992).

As regards one sentence updates, the subdivision into captions and pure updates does show a clear gender preference for one or the other - in the case of the pure updates a preference on the part of men can be recorded, viz. $12 \%$ of men (17 out of 140 ) vs. only $2 \%$ of women ( 3 out of 154). On the contrary, women tended to use this form far more often when uploading a photo in the profile update, i.e. $43 \%$ of women did it in the collected sample (66 times in 154 English-medium updates) as opposed to $34 \%$ of men (47 out of 140). It may therefore be surmised that when deciding to write a profile update in English, women from the Expanding Circle often do so while supporting themselves with a photo or a link there. Either this may mean a need for finding a justification for posting something altogether, i.e. writing something on the wall as long as there is something concrete to share, as e.g. an event or an object worth pointing out. Then it is done frequently in an all-inclusive way, i.e. in English, so that all or most of the women's contacts could access the message. It is naturally also to be observed with men, but on a smaller scale. On the other hand, as it seems on the basis of the rather marked discrepancy concerning the pure one-sentence posts, men feel more inclined to share their thinking with others, also by means of English, even if it is of a more abstract character or it may be a piece of news unsupported by a visual proof (cf. Holmes 1995).

The analysis of the one-sentence captions shows that women indeed like this form of commenting on the visual or audio elements which they upload on their profile, what is more, it is far more often than men in a similar situation that women do use these captions to provide some emotional comment on what their readers can see. Not infrequently are these photos of people or places, and women's comments, in this quite emphatic and often humorous a way, attract 
their friends' attention to their profiles and thus help maintain friendly contacts with them. The equivalent types of comments and posts to be found in men's updates are naturally not entirely different - there are also some emphatic comments with exclamation marks to be found, but the examples above show that it is relatively more frequent to see just an explanation, some information required for the proper understanding of the photo or a link, and possibly some evaluation of the content of the visual or audio attachment visible on the wall.

In summary, it may be said that the difference between the number of posts for both genders is rather remarkable. As concerns the content, most updates of this kind provide some concrete information about what has happened or will happen, or they have a form of a direct address to the profile owner's friends. More seldom do they pass on some abstract observations, therefore it may be concluded that using English in order to reach as wide an audience as possible takes place mostly in order to update them about some developments, rather than share observations of a more philosophical nature.

The analysis of the multi-sentence category, on the other hand, shows that women used 38 out of 154 (i.e. 25\%) updates of a more extensive character in English when describing photos, links, etc. attached to them, while men - only 25 of such a type of posts out of 140 (i.e. 18\%). Consequently, the reverse situation is true when we look at the pure comments - these, in the case of women, cover $19 \%$ of the updates (30 out of 154 ), and in the men's updates $24 \%$ (34 out of 140). Once again then, when it comes to profile updates, women tend to use English in connection with some additional element of the post, typically some visual enhancement, which appears to go hand in hand with the female field sensitivity and reference to concrete people or events (cf. Tannen 1994), whereas in the case of men updates may assume a more general, abstract character dissociated from a concrete event or person.

In summary of the two above categories some interesting comparison and conclusions may be drawn. Apart from the difference in the frequency between the caption and the pure type with regards to women and men, with women preferring the former, and men the latter, some differences in the form of these can be seen. While in the caption category the difference is not specially marked, as the descriptions are usually 2-3 lines long (even less) and usually contain some reference to the photo or the link attached, the pure category seems to stress the difference between men and women more visibly. While women tend to write such posts mainly in the form of an address directed towards their friends, mostly as wishes on some occasion or thanks for such wishes, and much more seldom as some general comments or deliberations, men's posts concern some events, issues one was involved in and the thoughts that they triggered, personal developments, longer quotes from books, and naturally also direct addresses and thanks. Also, on the whole, updates written by men tend to be much longer than in the case of females' posts. Thus, while posting in English, men appear to be bolder in the choice of topics and going beyond the 
prototypical use of Facebook posts, i.e. those used to maintain mutual contacts and passing on updates on personal issues. English is therefore also used quite frequently by men for passing on reports (Tannen 1991; Holmes 1995), while for women it serves as a means of building on rapport with their contacts (ibid.).

The use of quotes, on the other hand, unlike the previous category, does not seem to mark any additional symbolic role of the status of English on Facebook, except perhaps for indicating the fact that quoting texts in English (mostly song lyrics, books, words of some well know persons), and not infrequently long excerpts, proves that the profile owners must know and understand them as well as agree with, since putting them in their profile updates either reflects the profile owners' own mood or supports their own way of thinking. Thus, quoting in English indirectly corroborates the high status of this language as a means of communication in the discussed medium. The investigation of the profiles shows that there is a slight preference in terms of quoting on the part of men while women quoted other sources 8 times, men did it 10 times. The collected examples are excerpts from songs, some convey information about events, and also a certain percentage comes from books. On the basis of a limited sample collected, however, it is hard to draw a conclusion as to which of the above appears to be favoured by women, and which - by men, both in terms of the topic and the length of the quotes.

The comparison of the data in respect of the addressee of the posts, already adduced above, shows, somewhat surprisingly, that, contrary to earlier observations (cf. Tannen 1991), more men (27\%) rather than women (23\%) made use of personally directed updates. Yet, if we bear in mind that women chose to provide more personal information in visual elements of their updates than men, along with a suitable description, such a distribution of the forms of address appears easier to comprehend.

When women updated their profile in English in the $2^{\text {nd }}$ person, they mostly did it to thank others for wishes, also, less typically, to wish others well on various occasions. The addressees were mostly everyone among their contacts. Women less often encouraged others to do something. Men also thanked others for their wishes, however, their $2^{\text {nd }}$ person addresses more often constituted an invitation or a direct encouragement to do something, which leads to a conclusion that they tend to be bolder as regards taking inititative than is the case with women (who respond rather than provoke). This may be linked with an observation made by Dąbrowska (2013) concerning users of English as a native, second and foreign language where, in comparison with British and Indian women in particular, and all users in general, Polish women, and especially older ones, used English in their posts least of all, wrote shorter posts and formulated them in a very tentative way. The study linked this situation with their relative fear and shyness to use a foreign language in public contexts (Facebook is of course a private zone in terms of the topics covered, but public in its outreach). In the current study, where only posts of users of English as a foreign language are investigated, the plane of comparison is different, and 
the tentative character of female posts less marked, yet it may manifest itself in an alternative way - by means of a more passive, reactive and tentative character of updates on the part of women when compared to more pro-active and initiative-oriented approach of men.

Finally, the analysis of the update topics, though by no means easy, especially in the case of longer posts, presents itself as follows: women chose to refer to themselves and things immediately relevant to them 64 times ( $42 \%$ of all messages), and the more objective topic was selected 51 times (33\% of all). Men, on the other hand, opted for a personal topic 46 times (33\% of all updates) and for a more objective topic 64 times ( $46 \%$ of all). There is then a clear preference for women and men topic-wise, which, as can be seen, may also be detected in a foreign language medium, with women choosing to update others about what has happened or is happening in their own life more often, almost half of the times, while only in one third of the updates a reference is made to some more distant events and persons. The men's behaviour is quite reversed, with almost a half of them choosing to discuss something less personal and making some more private comments only in one third of the number of the cases. A similar pattern, though more complex due to the age variable, was also found in the posts of representatives of the Inner, Outer and Expanding Circles (Dąbrowska 2013).

In conclusion, it may be said that as regards the impersonal topics, naturally many aspects are touched upon, however, it may be observed that men do occasionally refer to political and social issues as well as some philosophical questions, there is also some criticism of certain aspects of reality. In the case of women the updates about other issues than personal ones refer more often to some events, like concerts or meetings, there might also be comments concerning views, most likely in connection with photos, seldom is there, however, a reference to social or political matters. On the other hand, in terms of personal updates, in the case of men the reference is made to some life events, like e.g. trips, some recollections from the past, less often to some feelings, emotions - and if so, they are rather negative than positive ones. In the group of female profile owners updates often concern other people, especially some nice developments that they were witnesses of, as celebrations, wishes, etc., moreover, women quite frequently refer to some aesthetic experiences and recommend them to others. It may then be concluded that although female and male profile owners use English in their updates to a similar extent, yet their preferences regarding the employment of the same forms tend to vary in terms of the frequency of use. 


\section{Conclusions}

The above discussion of both the form and the function of English-medium profile updates found on the walls of users of English as a foreign language in the Expanding Circle when juxtaposed to the use of their native language has led to a number of observations. It has been discovered that both their native language and English are used in profile updates, with English used in more than a half of them. The decision to write an update in English, as the survey results have demonstrated, is primarily dictated by the fact that English is nowadays the most international language of the modern world (and thus the property shared and owned commonly, also by the users from the Expanding Circle), another reason being that many of the friends one has on Facebook are foreigners. English is chosen because it feels most natural to use it on Facebook, and because it has become a part of one's Facebook identity. It can be seen that one also uses English with people who come from one's own country. All the above reasons point to a special role of the language (the sense of its common ownership and the symbolic use), which enhances the use of English as a shared repertoire in the community of practice (cf. Eckert \& McConnell-Ginet 1992, Trousdale 2010).

The analysis of the profile updates in terms of gender of the users has demonstrated that there was a clear preference for women and men topic-wise, detected also in the English language medium, which, in turn, was also correlated with the formal aspects (the length of the posts and updates addressees). Women chose to update others about their private life almost half of the times, and only in one third of the updates did they make a reference to some more distant events and persons, while men's behaviour was quite the reverse, with almost a half of them choosing to discuss something less personal in English and making some more private comments only in one third of all the cases. Another difference observed was that while women made their posts more personal, and more reactive (e.g. thanking others for something or giving wishes on certain occasions), men preferred to encourage the addressees to undertake some action. These observations to a large extent confirm findings concerning gender differences in the use of language found in the offline world (cf. Tannen 1991, Holmes 1995).

Formally, the updates could be divided into one-sentence updates and multisentence updates (with a subdivision into captions and pure updates), switches (single-word vs. intersentential), the latter type explored relatively seldom (despite a frequent indication of this option in the survey), and with a similar distribution among men and women, and finally quotes. Most of the sentences analysed were formed properly in terms of grammar and lexis as well as their pragmatics, which proves that women and men from the Expanding Circle have also thoroughly embraced the use of English as their own code and adopted it for their own Facebook-internal use, though with the gender-preferential differences listed above. 
The observations made here on the basis of the analysed updates as well as the survey results implicate that online communication via social media, which encourages a spontaneous and relaxed way of self-expression, is a good tool for studying both the character of English as a global language and gender differences in the use of language also in the written form, so far largely neglected in sociolinguistic studies. These differences appear to be detected in the behaviour of women and men irrespective of their nationality and also the language chosen to write one's updates in, both native and foreign. As regards the foreign language, the study has demonstrated that in the present day the English language appears as often, if not more, as the native tongue in the updates of users from the Expanding Circle too, having been adopted by them to a large extent as a marker of their identity online, and possibly offline too, which remains to be investigated. This testifies to a continuous spread of English as a lingua franca through various channels in the modern world, and the findings made here may lead to a conclusion that, in keeping with the claims made by some scholars cited above (cf. Hinrichs 2006, Deumert 2014, Tagg and Seargeant 2014) English has gradually been assuming the role of a social media register - and thus a social media we-code - for its non-native users, who are also able to adapt it skilfully to their personal needs and character.

\section{References}

Al Kaddour, Noor and Rana Kaddoura. 2019. The use of code-switching and code-mixing by speakers of Emirati Arabic (EA). Journal of Literatures, Language and Linguistics 52, 59-63. https://doi.org/10.7176/JLLL/52-08

Bassam, Loubna. 2017. Gender Differences in SMS Code-Switching by Lebanese Undergraduates. Unpublished doctoral thesis. Universitat Rovira i Virgili. Tarragona

Bell, Allan. 1984. Language style as audience design. Language in Society 13(2), 145-204. https://doi.org/10.1017/S004740450001037X.

Blom, Jan-Petter and John J. Gumperz. 1972. Social meaning in linguistic structures: codeswitching in Norway. In: Directions in Sociolinguistics: The Ethnography of Communication,ed. by J. J. Gumperz and D. Hymes. New York and Oxford: Basil Blackwell, 407-434.

Blommaert, Jan. 2010. The Sociolinguistics of Globalization. Cambridge: Cambridge University Press. https://doi.org/10.1017/CBO9780511845307

Cheshire, Jenny and Penelope Gardner-Chloros. 1997. Communicating gender in two languages. In: Communicating Gender in Context, ed. by H. Kothoff and R. Wodak. Amsterdam: John Benjamins, 249-283. https://doi.org/10.1075/pbns.42.12che

Cheshire, Jenny and Penelope Gardner-Chloros. 1998. Code-switching and sociolinguistic gender pattern. International Journal of the Sociology of Language 129, 5-34. https://doi.org/10.1515/ijsl.1998.129.5

Clyne, Michael. 2003. Dynamics of Language Contact: English and Immigrant Languages. Cambridge: Cambridge University Press. https://doi.org/10.1017/CBO9780511606526

Dąbrowska, Marta. 2013. Variation in Language: Faces of Facebook English. Frankfurt am Main: Peter Lang.

Deumert, Ana. 2014. Sociolinguistics and Mobile Communication. Edinburgh: Edinburgh University Press. 
Dorleijn, Margreet and Jacomine Nortier. 2009. Code-switching and the Internet. In: The Cambridge Handbook of Linguistic Code-switching, ed. by B. E. Bullock and A. J. Toribio . Cambridge: Cambridge University Press, 127-141. https://doi.org/10.1017/CBO9780511576331.009

Eckert, Penelope and Sally McConnell-Ginet. 1992. Think practically and look logically: Language and gender as community-based practice. Annual Review of Anthropology 21/4, 21-6. https://doi.org/10.1146/annurev.an.21.100192.002333

Gardner-Chloros, Penelope. 1991. Language Selection and Switching in Strasbourg. Oxford: Oxford University Press.

Gardner-Chloros, Penelope. 2009. Code-Switching. Cambridge: Cambridge University Press. https://doi.org/10.1017/CBO9780511609787

Gardner-Chloros, Penelope and Katerina Finnis. 2004. How code-switching mediates politeness: gender-related speech among London Greek-Cypriots. Estudios de Sociolinguistica. Special Issue: Language and Gender: An Interdisciplinary Perspective, 4(2), 505-533. https://doi.org/10.1558/sols.v4i2.505

Graddol, David. 2006. English Next. Why Global English May Mean the End of "English as a Foreign Language”. London: British Council.

Gumperz, John J. 1982. Discourse Strategies. Cambridge: Cambridge University Press. https://doi.org/10.1017/CBO9780511611834

Hinrichs, Lars. 2006. Codeswitching on the Web: English and Jamaican Creole in E-mail Communication. Amsterdam and Philadelphia: John Benjamins. https://doi.org/10.1075/pbns.147

Holmes, Janet. 1995. Women, Men and Politeness. London and New York: Longman.

Ismail, Manal A. 2015. The Sociolinguistic Dimensions of code-switching between Arabic and English by Saudis. International Journal of English Linguistics 5 (5), 99-109. https://doi.org/10.5539/ijel.v5n5p99

Kachru, Braj Bihari. 1992. The second diaspora of English. In: English in its Social Contexts: Essays in Historical Linguistics, ed. by T.W. Machan, and C.T. Scott. New York and Oxford: Oxford University Press, 230-252.

Mills, Sara and Louise Mullany. 2011. Language, Gender and Feminism. Theory, Methodology and Practice. Oxford: Routledge. https://doi.org/10.4324/9780203814666

Mushtaq, Hammad. 2012. Gender difference in code-switching and code-mixing in text messages of undergraduate students. Language in India 12, https://ssrn.com/abstract=2196930.

Muysken, Pieter. 2000. Bilingual Speech: A Typology of Code-mixing. Cambridge: Cambridge University Press.

Myers-Scotton, Carol. 1993. Social Motivation for Codeswitching: Evidence from Africa. Oxford: Clarendon Press.

Nortier, Jacomine. 1990. Dutch-Moroccan Arabic Code Switching. Dordrecht: Foris Publications.

Panhwar, Farida, Saima Murtaza Pandihiani and Ameer Ali Buriro. 2018. Code-switching and gender identity. The Women 10, 42-59.

Pennycook, Alastair. 2007. Global Englishes and Transcultural Flows. London: Routledge. https://doi.org/10.4324/9780203088807

Poplack, Shana. 1980. Sometimes I'll start a sentence in Spanish Y TERMINO EN ESPANOL: Toward a typology of code-switching. Linguistics 18. 581-618. https://doi.org/10.1515/ling.1980.18.7-8.581

Sebba, Mark and Tony Wootton. 1998. We, they and identity: sequential vs. identity-related explanation in code-switching. In: Code-Switching in Conversation, ed. by P. Auer. London: Routledge, 262-290.

Seidlhofer, Barbara. 2007. English as a lingua franca and communities of practice. In: Anglistentag 2006 Halle Proceedings, ed. by S. Volk-Birke and J. Lippert. Trier: Wissenschaflicher Verlag, 307-318. 
Tagg, Caroline and Philip Seargeant. 2014. Audience design and language choice in the construction and maintenance of translocal communities on social network sites. In: The Language of Social Media: Identity and Community on the Internet, ed. by P. Seargeant and C. Tagg. London: Palgrave Macmillan, 161-185. https://doi.org/10.1057/9781137029317_8

Tannen, Deborah. 1991. You Just Don't Understand: Women and Men in Conversation. New York: Ballantine Books.

Tannen, Deborah. 1994. Gender and Discourse. New York and Oxford: Oxford University Press.

Treffers-Daller, Jeanine.1994. Mixing Two Languages. French-Dutch Contact in a Comparative Perspective. Berlin: Mouton de Gruyter. https://doi.org/10.1515/9783110882230

Trousdale, Graeme. 2010. An Introduction to English Sociolinguistics. Edinburgh: Edinburgh University Press.

Wardhaugh, Ronald. 1992 (2 ${ }^{\text {nd }}$ ed.). An Introduction to Sociolinguistics. Oxford: Blackwell.

Wenger, Étienne. 1998. Communities of Practice. Cambridge: Cambridge University Press. 